\title{
High Allelopathic Activity of Carotenoid-accumulating Callus of a Halophilic Mangrove Plant, Avicennia alba: Protoplast Co-culture Method with Digital Image Analysis
}

\author{
Hamako Sasamoto $^{1,2}$, Manabu Hayatsu ${ }^{1,3} \&$ Suechika Suzuki $^{1}$ \\ ${ }^{1}$ Research Institute for Integrated Science, Kanagawa University, Hiratsuka, Kanagawa 259-1293, Japan \\ ${ }^{2}$ Department of International Environmental and Agricultural Sciences, Tokyo University of Agriculture and \\ Technology, Fuchu, Tokyo 183-8509, Japan \\ ${ }^{3}$ Division of Microscopic Anatomy, Graduate School of Medical and Dental Sciences, Niigata University, \\ Niigata, 951-8510, Japan \\ Correspondence: Hamako Sasamoto, Department of International Environmental and Agricultural Science, \\ Tokyo University of Agriculture and Technology, Fuchu, Tokyo 183-8509, Japan. Tel: 81-42-367-5625. E-mail: \\ sasamoto@ynu.ac.jp
}

Received: October 23, 2019

Accepted: November 18, 2019 Online Published: December 4, 2019

doi:10.5539/jps.v9n1p1

URL: https://doi.org/10.5539/jps.v9n1p1

\begin{abstract}
A yellow callus strain was established from hypocotyls of a halophilic mangrove plant, Avicennia alba, by subculture in the dark. Allelopathic activities of yellow A. alba callus were assayed using recipient lettuce protoplasts at three growth stages by the protoplast co-culture method with digital image analysis. The protoplast cultures of yellow A. alba callus were halophilic to $\mathrm{NaCl}, \mathrm{KCl}$, and $\mathrm{MgCl}_{2}$ (up to $200 \mathrm{mM}$ ) but not to $\mathrm{CaCl}_{2}$. $\mathrm{By}$ contrast, $\mathrm{NaCl}$ and $\mathrm{KCl}$ inhibited the growth of non-salt-tolerant lettuce protoplasts, while $\mathrm{CaCl}_{2}$ and $\mathrm{MgCl}_{2}$ stimulated their growth at low concentrations. Highly salt-tolerant or halophilic mangrove plant cells were expected to have low allelopathic activity, but the protoplasts of yellow A. alba callus had very strong allelopathic activity. The inhibition was strongest at the cell division stage with growth being inhibited to $50 \%$ and $9 \%$ of the control by $10^{4} \mathrm{~mL}^{-1}$ and $5 \times 10^{4} \mathrm{~mL}^{-1}$ of A. alba, respectively. There was less inhibition at the yellow pigment accumulation stage of lettuce. Stimulation was observed at the early cell wall formation stage with up to $10^{5} \mathrm{~mL}^{-1}$ of $A$. alba. The yellow pigment of yellow A. alba callus was extracted with hexane and its absorption spectrum showed the wavelength peaks of a carotenoid, neoxanthin. Using transmission electron microscopy, specific electron-dense structures were found in yellow A. alba callus, which were similar to the undeveloped ultrastructure of a carotenoid. A carotenoid was strongly suggested to be the putative allelochemical in yellow callus of $A$. alba.
\end{abstract}

Keywords: allelopathy, carotenoids, mangrove plant cells, protoplast culture, salt tolerance, ultrastructure

\section{Introduction}

\subsection{Salt Tolerance and Allelopathy of Cultured Mangrove Cells}

Mangrove plants are mainly tree species growing in brackish water varying in salinity in the tropical and subtropical areas (Tomlinson, 1986; Spalding et al., 2010). Salt tolerance is a strategy to survive in a high salinity environment. Tissue-cultured cells of several mangrove plants, growing in the coastal region with a high salinity show strong salts tolerance at the cellular level (Kawana \& Sasamoto, 2008; Hayashi et al., 2009; Yamamoto et al., 2011). Protoplasts of suspension-cultured cells from cotyledons of Sonneratia alba and Avicennia alba, which are distributed in the seaward-side area, were found to be halophilic to $\mathrm{NaCl}$ (Hasegawa et al., 2013). The cellular distribution of salts elements, $\mathrm{Na}, \mathrm{K}, \mathrm{Mg}, \mathrm{Ca}, \mathrm{Cl}, \mathrm{P}$ and $\mathrm{S}$, in suspension-cultured cells of S. alba (Hayatsu et al., 2014) and A. alba (Hayatsu et al., 2017) were investigated using quantitative X-ray microanalysis of cryosections to study the cellular mechanism(s) of strong salt tolerance or halophilism.

Allelopathy is a strategy of plants that cannot move away from unfavorable environment, to survive by inhibiting the growth of neighboring plants through production of allelochemicals. Allelopathic activities of many non-mangrove test plants have been studied by the in vitro bioassay method (the sandwich method with dried 
leaves) using lettuce seedlings as a recipient plant (Fujii, 2000; Fujii et al., 2003; Bergum et al., 2019). The protoplast co-culture method for in vitro bioassay of allelopathy using lettuce protoplasts as the recipient was recently developed for examining not only herbaceous plant species, e.g., leguminous Mucuna pruriens (Sasamoto et al., 2013) and Vicia villosa (Sasamoto et al., 2019), and Arabidopsis thaliana (Sasamoto et al., 2017b), but also woody and tree plant species, e.g., bamboo species (Ogita \& Sasamoto, 2017), and Prunus species (Fujise et al., 2018), and a tropical invader leguminous tree plant, Leucaena leucocephala (Mori et al., 2015). We developed a protoplast co-culture method with digital image analysis, to quantify the effects on the yellow pigment accumulation during lettuce protoplast growth (Ogita \& Sasamoto, 2017; Sasamoto et al., 2017a, b, 2018, 2019).

Using the sandwich method, dried leaves of 16 mangrove species were tested (Sasamoto et al., 2014). Their inhibitory allelopathic activities were higher in upstream grown species and lower in seaward-side-grown species including Avicennia marina. Allelopathic activity of Bruguiera sexangula was in-between, and its suspensioncultured cells (Kawana \& Sasamoto, 2008) and their protoplasts (Fukumoto et al., 2004) were tolerant to $\mathrm{NaCl}$ but not halophilic.

Studies on allelopathy of mangrove plants at cellular level were started after the in vitro bioassay methods of allelopathy using tissue cultured cells and their protoplasts were developed (Hasegawa, 2014). An inverse relationship had been found between allelopathic activity and salt tolerance at both the plant level and cellular level in three Sonneratia mangrove species which can grow in most seaward-side ( $S$. alba) and upstream areas $(S$. caseolaris) and in-between (S. ovata) using dark-grown suspension-cultured cells (Hasegawa et al., 2014). High allelopathic activities have been found using both the sandwich method and protoplast co-culture method in a leguminous tree mangrove, Derris indica, which grows in the upstream area (Inoue et al., 2015). Such an inverse relationship between salt tolerance and allelopathic activities might be widely applicable to different mangrove plant species (Hasegawa, 2014; Sasamoto et al., 2014).

\subsection{Allelochemicals of Mangrove Cells}

The inhibitory effects of putative allelochemicals in plants, e.g., L-DOPA in Mucuna (Sasamoto et al., 2013; Mori et al., 2015); purine alkaloids, caffeine metabolites (Sasamoto et al., 2015a); pyridine alkaloids, mimosine in L. leucocephala (Mori et al., 2015); nicotinic acid, nicotinamide and trigonelline (Sasamoto \& Ashihara, 2014); abscisic acid and coumarin in Prunus (Fujise et al., 2018); canavanine and cyanamide in Vicia (Sasamoto et al., 2019) have been determined using the same lettuce protoplast co-culture method. However, mangrove cultured cells have not been examined for putative allelochemicals, except for an isoflavonoid, rotenone, in $D$. indica (Inoue et al., 2015). Very recently, a natural pigment, an anthocyanin, cyanidin 3,5-di- $O$-glucoside (cyanin), was identified in red callus of $S$. ovata originated from cotyledons, which was long sub-cultured in the light condition. Allelopathic activities of an anthocyanin was first evaluated using the protoplast co-culture method with digital image analysis (Sasamoto et al., 2018). The stronger allelopathic activity was found in the red callus of $S$. ovata than in dark-grown suspension-cultured cells (Hasegawa et al., 2014).

The function of another natural pigment, carotenoid, is usually discussed relative to chlorophyll in photosynthesis. The ultrastructure of plastids in carotenoids-containing tissues and different absorption spectra of extracted carotenoids was investigated during the ripening of fruits (Aoki et al., 2011; Hayatsu et al., 2016). Very recently, a report on a carotenoid-containing carrot root callus line cultured in the dark worked on the ultrastructure of their plastids (Oleszkiewicz et al., 2018). However, to our knowledge, there have been no reports on carotenoids in relation to their allelopathic activities.

Yellow callus of Avicennia alba originating from hypocotyls (Tsuchiya et al., 2013) and sub-cultured in the dark for a long period, was used in this study. We examined the effects of four salts, $\mathrm{NaCl}, \mathrm{KCl}, \mathrm{MgCl}_{2}$, and $\mathrm{CaCl}_{2}$ on the protoplast culture of yellow A. alba callus. They were compared with the effects on lettuce protoplasts, which is the recipient in the bioassay of allelopathy. Then, the allelopathic activities of yellow A. alba callus on three stages of lettuce protoplast growth were examined using the protoplast co-culture method with digital image analysis. The pigment was analyzed spectrophotometrically, and the ultrastructure of plastids in the yellow callus cells of A. alba was investigated using transmission electron microscopy. A new function of a carotenoid in strong allelopathic activity was discussed.

\section{Method}

\subsection{Callus culture of Avicennia alba}

As described previously (Tsuchiya et al., 2013), the callus culture of Avicennia alba was induced from hypocotyls from a germinated seed stored in tap water, using modified amino acid (mAA) basal medium 
(Hasegawa et al., 2013; Thompson et al., 1986), containing $1 \mu \mathrm{M}$ 2,4-dichlorophenoxyacetic acid (2,4-D), $1 \mu \mathrm{M}$ thidiazuron and $3 \%$ sucrose solidified with $0.8 \%$ agar. The basal medium contains various elements as the major salt components ( $0.2 \mathrm{mM} \mathrm{Na}, 21.25 \mathrm{mM} \mathrm{K}, 1.5 \mathrm{mM} \mathrm{Mg}, 3 \mathrm{mM} \mathrm{Ca}, 26 \mathrm{mM} \mathrm{Cl})$. Pure water (Milipore Direct Q $\mathrm{UV}, 18.2 \mathrm{M} \Omega$ ) was used for all culture media preparation. The $\mathrm{pH}$ was adjusted to 6.2 with $\mathrm{NaOH}$ and then autoclaved at $121{ }^{\circ} \mathrm{C}, 20 \mathrm{~min}$. The yellow callus was selected and sub-cultured more than 4 years, at 4 - to 8 -week intervals in 6-9 $\mathrm{cm}$ Petri dishes or $100 \mathrm{~mL}$ flasks. The cultures were kept at $27-30^{\circ} \mathrm{C}$ in the dark.

\subsection{Lettuce Seedlings}

Lactuca sativa (lettuce) seedlings were prepared as described previously (Sasamoto et al., 2013). Briefly, lettuce seeds (Great Lakes) in a small bag of Miracloth were washed with a neutral detergent and tap water, and sterilized with $1.5 \% \mathrm{NaClO}$ solution for $15 \mathrm{~min}$ and washed three times with autoclaved water. They were aseptically cultured on $0.8 \%$ agar medium in the light condition $\left(60 \mu E \mathrm{~s}^{-1}\right)$ for $6-8$ days at $25^{\circ} \mathrm{C}$.

\subsection{Protoplast Isolation of A. alba Callus and of Lettuce Cotyledons}

Protoplasts of A. alba callus were isolated as described previously (Tsuchiya et al., 2013), in 1\% each of Cellulase RS and Driselase 20 in $0.6 \mathrm{M}$ mannitol solution for $24 \mathrm{hrs}$ at $80 \mathrm{rpm}$ speed at $25-28^{\circ} \mathrm{C}$. After filtration through $95 \mu \mathrm{m}$ nylon mesh and sucrose $(0.6 \mathrm{M})$ density gradient centrifugation, the middle layer was washed three times with $0.6 \mathrm{M}$ mannitol solution by centrifugation at $1400 \mathrm{rpm}(300 \mathrm{~g})$ for $5 \mathrm{~min}$. Protoplasts of lettuce cotyledons were isolated in 1\% each of Cellulase RS and Macerozyme R10 (Sasamoto et al., 2013) in 0.6 M mannitol solution for $24 \mathrm{hrs}$ at static condition. After filtration through $80 \mu \mathrm{m}$ mesh, the protoplasts were washed three times with $0.6 \mathrm{M}$ mannitol solution by centrifugation at $900 \mathrm{rpm}(100 \mathrm{~g})$ for $5 \mathrm{~min}$.

\subsection{Salts Effects on Protoplast Cultures of A. alba and Lettuce}

Liquid MS basal medium (Murashige \& Skoog, 1962) containing $1 \mu \mathrm{M}$ 2,4-D, $0.1 \mu \mathrm{M}$ benzyladenine (BA) and $3 \%$ sucrose and $0.4 \mathrm{M}$ mannitol was used, which contained the same concentrations of elements, $\mathrm{Na}, \mathrm{K}, \mathrm{Mg}, \mathrm{Ca}$, of the mAA medium for callus culture (2.1) except for $6 \mathrm{mM} \mathrm{Cl}$. The $\mathrm{pH}$ was adjusted to 5.8 with $\mathrm{KOH}$ before autoclaving. Liquid medium (50 $\mu \mathrm{l}$ ) containing additional $0,10,25,50,100$ or $200 \mathrm{mM}$ of $\mathrm{NaCl}, \mathrm{KCl}, \mathrm{MgCl}_{2}$, or $\mathrm{CaCl}_{2}$ to the basal medium was added to 96 well culture plates (Falcon No. 3075) by mixing the zero additional medium with $200 \mathrm{mM}$ additional medium of each salt. To each well was added $5 \mu 1$ of protoplast suspension of ten times final density. Final protoplast densities of $A$. alba and of lettuce were $6-50 \times 10^{3} \mathrm{~mL}^{-1}$. One hundred $\mu 1$ of autoclaved pure water was supplied to the space in between the wells. After sealing with Parafilm, they were cultured in the dark at $28^{\circ} \mathrm{C}$ in a humid incubator $\left(\mathrm{CO}_{2}\right.$-incubator without the supply of $\mathrm{CO}_{2}$ gas, APC-30DR, ASTEC Co. Ltd.). After 5 and 12 days of culture of A. alba protoplasts, and after 4 and 8 days of culture of lettuce protoplasts, the numbers of non-spherically enlarged and divided protoplasts were counted under an inverted microscope (Olympus IX-71). Yellow pigment accumulation of lettuce protoplasts after 28 and 34 days of culture was analysed using digital image analysis (2.6). Percentages of control values without additional salts were calculated, and then averaged with standard error (SE) at different (initial) protoplast densities of A. alba or lettuce.

\subsection{Protoplast Co-culture of A. alba and Lettuce}

MS basal medium (50 $\mu \mathrm{l}$ ) containing $1 \mu \mathrm{M}$ 2,4-D, $0.1 \mu \mathrm{M}$ BA, 3\% sucrose and $0.6 \mathrm{M}$ mannitol was used. Five $\mu \mathrm{l}$ each of protoplast suspensions of $A$. alba and lettuce in $0.6 \mathrm{M}$ mannitol solution were added to each well. Final protoplast densities were $3 \times 10^{3} \mathrm{~mL}^{-1}$ to $3 \times 10^{5} \mathrm{~mL}^{-1}$ for $A$. alba and $6 \times 10^{3} \mathrm{~mL}^{-1}$ to $10^{5} \mathrm{~mL}^{-1}$ for lettuce. Numbers of non-spherically enlarged and divided lettuce protoplasts were counted under an inverted microscope after 5 days of co-culture, and numbers of divided cells including colonies composed of more than four cells were counted after 12 days of co-culture. Yellow pigment accumulation of lettuce protoplasts after 33 days of co-culture was analyzed using digital image analysis (2.6). Percentages of control values without A. alba protoplasts were calculated and then, the percentages of control at different densities of lettuce protoplasts were averaged with SE.

\subsection{Digital Image Analysis of 96 Well Culture Plate}

Image analysis of yellow pigment accumulation of lettuce protoplasts after about one month of (co-) culture was performed as described previously (Ogita \& Sasamoto 2017; Sasamoto et al., 2017-2019). Digital image of a 96-well culture plate was scanned using a scanner (Epson GTX-970). Image analysis by software Image J (NIH, Rasband, 1997-2016) was performed. An image was selected from the blue channel. A horizontal straight line was drawn at the center of the wells. The plot profile of the line was analyzed. Using excel software, we determined the average of blue plot values for each well. The yellow value was converted by deduction of each averaged blue value from the highest blue value (control). The yellow values were deduced at each density of $A$. 
alba protoplasts. The \% yellow value of control without $A$. alba protoplasts or additional salts was calculated at each lettuce protoplast density. Finally, the percentages of control were averaged with SE at different cell densities of lettuce $\left(6 \times 10^{3} \mathrm{~mL}^{-1}\right.$ to $\left.10^{5} \mathrm{~mL}^{-1}\right)$.

\subsection{Extraction of Carotenoid from Yellow A. alba Callus}

Yellow A. alba callus was extracted with $i$-propanol $\left(\mathrm{CaCO}_{3}\right.$ was added) in a mortar with a pestle as previously reported (Aoki et al., 2011). The yellow fraction was extracted using n-hexane. Dehydrated with anhydrous $\mathrm{Na}_{2} \mathrm{SO}_{4}$. Wavelength spectrum was obtained using dual-wavelength spectrophotometer (V-630, JASCO Corporation). A carotenoid was identified from the wavelength peaks of extracts in hexane (Davies, 1965). The carotenoid content was calculated using a molar extinction coefficient (136000 at $438 \mathrm{~nm}$ in ethanol).

\subsection{Transmission Electron Microscopy}

Callus of A. alba was mixed with agarose (Type VII, Sigma A-4018), which was dissolved (2\%) in liquid medium at $60^{\circ} \mathrm{C}$ for $20 \mathrm{~min}$, and solidified at room temperature. Callus in agarose block was fixed with a $6 \%$ glutaraldehyde solution ( $0.1 \mathrm{M}$ phosphate buffer, $\mathrm{pH}$ 7.2) for $12 \mathrm{~h}$ and post-fixed with a $2 \%$ osmium tetroxide solution at $4{ }^{\circ} \mathrm{C}$ overnight. The fixed specimens were dehydrated with a graded series of acetone and embedded in epoxy resin Quetol 812 (Nisshin EM Co. Ltd., Tokyo, Japan). Ultrathin sections of $\sim 70 \mathrm{~nm}$ thickness were cut using ultramicrotome (Ultracut-N; Reichert-Jung, Vienna, Austria), and stained with uranyl acetate and lead citrate. The sections were examined with a transmission electron microscope (H-7650, Hitachi Ltd., or JEM-2100EX, JEOL, Akishima, Tokyo, Japan) operated at an accelerating voltage of $80 \mathrm{kV}$ or $100 \mathrm{kV}$ as described previously (Aoki et al., 2011; Hayatsu et al., 2014, 2016, 2017).

\section{Results}

\subsection{Protoplast Isolation of Yellow Avicennia alba Callus}

Protoplasts were isolated from A. alba callus, and structural features were observed under an inverted microscope (Figure 1). Callus of A. alba grown in the dark was yellow (Figure 1a), and cell aggregates were observed in water (Figure 1b). Isolated protoplasts were spherical and 20-60 $\mu \mathrm{m}$ in diameter (Figure 1c). The yellow color was distinct in the concentrated protoplasts solution of yellow A. alba callus (data not shown).
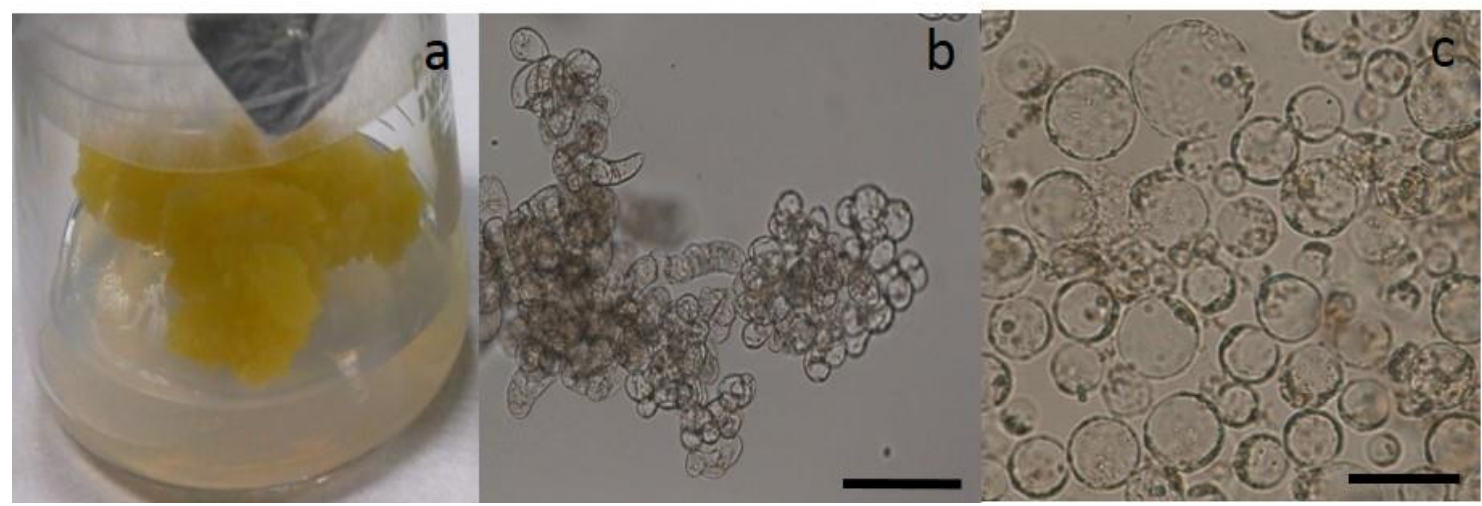

Figure 1. Photographs of yellow Avicennia alba callus (a) after two months of culture in a $100 \mathrm{~mL}$ flask, cell aggregates (b), and their protoplasts (c). Bar=100 $\mu \mathrm{m}$ (b) and $50 \mu \mathrm{m}$ (c).

\subsection{Effects of Four Salts on the Protoplasts Growth of Yellow A. alba Callus}

In the protoplast cultures of yellow A. alba callus, halophilic nature to $\mathrm{NaCl}$ was clearly observed after 12 days of culture, at the cell division stage, when the percentage of divided cells was $43 \%$ without additional salts (Figure 2b). Furthermore, halophilism to $\mathrm{KCl}$ and $\mathrm{MgCl}_{2}$ was also observed at up to $200 \mathrm{mM}$. However, $\mathrm{CaCl}_{2}$ inhibited growth at all concentrations tested. Inhibition by $\mathrm{Ca}^{2+}$ ions was also obtained after 5 days of culture, at the early cell wall formation stage, when almost no cell division was observed (Figure 2a). 

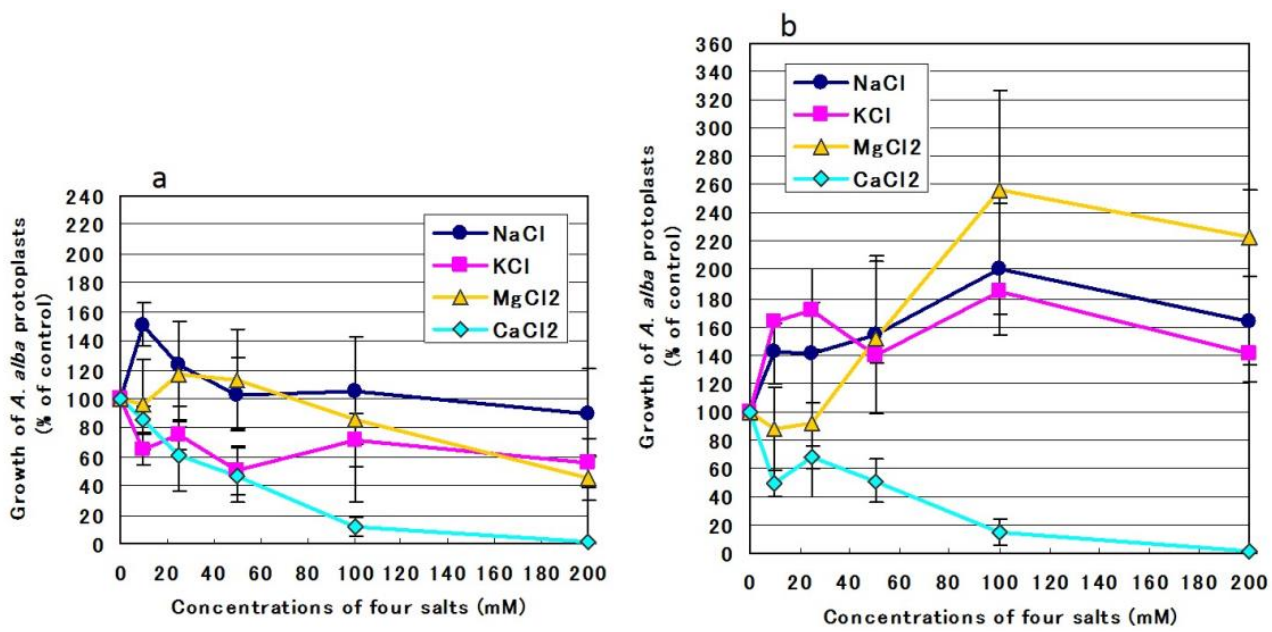

Figure 2. Effects of $\mathrm{NaCl}, \mathrm{KCl}, \mathrm{MgCl}_{2}$, and $\mathrm{CaCl}_{2}$ on the growth of Avicennia alba protoplasts after 5 days (a) and 12 days (b) of culture. The medium was MS basal medium containing $1 \mu \mathrm{M} 2,4-\mathrm{D}, 0.1 \mu \mathrm{M}$ BA, 3\% sucrose, and 0.4 M mannitol.

\subsection{Effects of Four Salts on the Protoplasts Growth of Lettuce}

In contrast to $A$. alba protoplasts (section 3.2), the effect of salt on the cell wall formation and cell division was totally different in lettuce protoplasts as shown in Figure 3. After 4 days of culture (Figure 3a), at the cell wall formation stage, the percentage of divided cells was only $7 \%$ in the control without additional salts. After 8 days of culture (Figure 3b), only the numbers of divided protoplasts including colonies composed of more than four cells, were counted. $\mathrm{NaCl}$ was inhibitory at all concentrations tested. $\mathrm{KCl}$ was less inhibitory at up to $100 \mathrm{mM}$. $\mathrm{MgCl}_{2}$ and $\mathrm{CaCl}_{2}$ stimulated growth at low concentrations $(10-25 \mathrm{mM})$, but inhibited it strongly at high concentrations (100 $\mathrm{mM}$ or more).
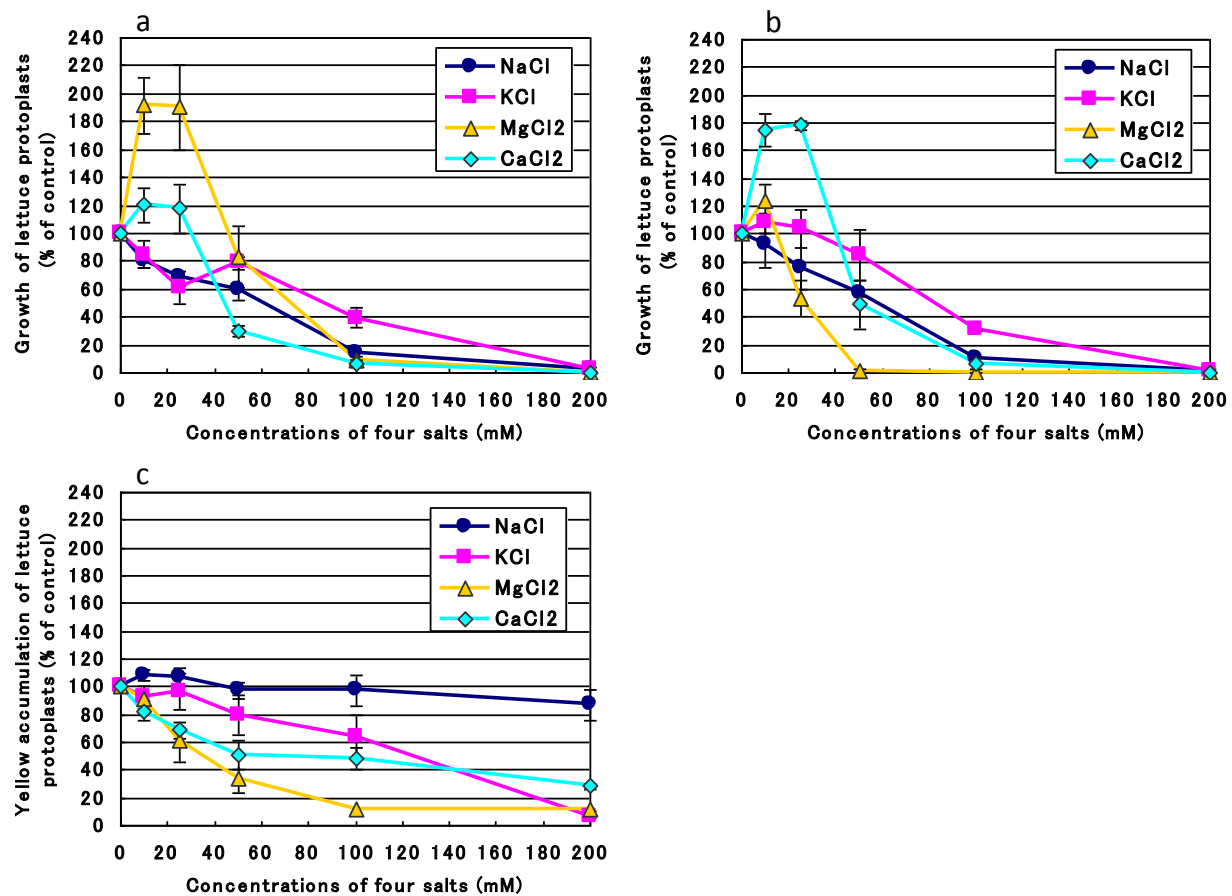

Figure 3. Effects of $\mathrm{NaCl}, \mathrm{KCl}, \mathrm{MgCl}_{2}$, and $\mathrm{CaCl}_{2}$ on the growth of lettuce protoplasts after 4 days (a), and 8 days (b) of culture, and their effects on the yellow pigment accumulation in the lettuce protoplasts after 34 days of culture (c). The medium was MS basal medium containing $1 \mu \mathrm{M} 2,4-\mathrm{D}, 0.1 \mu \mathrm{M}$ BA, 3\% sucrose and $0.4 \mathrm{M}$ mannitol. 
Yellow pigment accumulation in lettuce protoplasts was hardly inhibited by $\mathrm{NaCl}$ but was inhibited by other salts tested after 34 days of culture (Figure $3 \mathrm{c}$ ). $\mathrm{MgCl}_{2}$ and $\mathrm{CaCl}_{2}$ inhibited growth more strongly than $\mathrm{KCl}$ at up to $100 \mathrm{mM}$. The pattern of inhibition was similar after 28 days of culture except for slight inhibition at $200 \mathrm{mM}$ of $\mathrm{NaCl}$ (data not shown).

\subsection{Allelopathic Activities of Yellow A. alba Callus: Protoplast Co-culture with Digital Image Analysis}

Green protoplasts of lettuce were co-cultured with yellow A. alba callus protoplasts as shown in Figure 4, and the effect of $A$. alba protoplasts was examined at three different stages of lettuce protoplast growth using the protoplast co-culture method (Figure 5). After 5 days of co-culture, at the early cell wall formation stage of lettuce protoplasts, stimulation by $A$. alba protoplasts was prominent up to $10^{5} \mathrm{~mL}^{-1}$ and rapid reduction of growth was seen at $3 \times 10^{5} \mathrm{~mL}^{-1}$.

Strong inhibition was observed at the cell division stage of lettuce protoplast growth after 12 days of co-culture. Lettuce protoplasts showed less than $50 \%$ and $10 \%$ growth of control (without $A$. alba), at $10^{4} \mathrm{~mL}^{-1}$ and at $5 \times$ $10^{4} \mathrm{~mL}^{-1}$ of $A$. alba, respectively. Inhibition by $A$. alba protoplasts were more than $50 \%$ and $90 \%$, respectively.

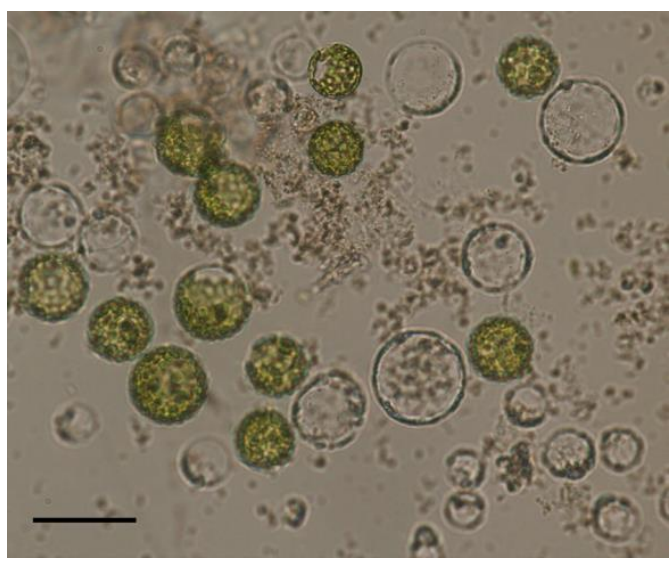

Figure 4. Green lettuce protoplasts co-cultured with protoplasts of yellow callus of Avicennia alba.

Photographed on the first day of culture. Bar $=50 \mu \mathrm{m}$.

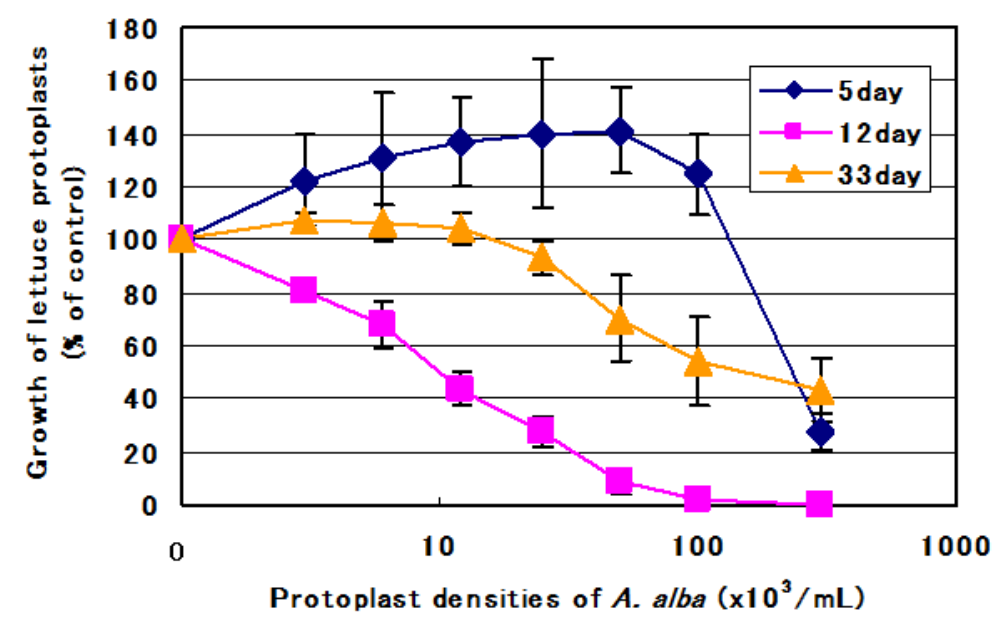

Figure 5. Growth of lettuce protoplasts after 5 days (cell wall formation), 12 days (cell division), and 33 days (yellow pigment accumulation) of co-culture with protoplasts of yellow callus of Avicennia alba. Medium was

MS basal medium containing $1 \mu \mathrm{M}$ 2,4-D, $0.1 \mu \mathrm{M}$ BA, 3\% sucrose and $0.6 \mathrm{M}$ mannitol.

Inhibition of yellow pigment accumulation of lettuce protoplasts by A. alba protoplasts was investigated using the digital image analysis of scanned 96-well culture plate after 33 days of co-culture. Less inhibition by A. alba protoplasts was observed at the yellow pigment accumulation stage compared with those at the cell division 
stage of lettuce protoplasts (Figure 5).

\subsection{Carotenoid Extraction from Yellow A. alba Callus}

A wavelength spectrum of hexane extracts from yellow A. alba callus was shown in Figure 6. Neoxanthin was identified from the peaks at 421, 439, $466 \mathrm{~nm}$ in hexane (Davies, 1965). The content of neoxanthin was calculated to be about 4 nmoles / $\mathrm{g}$ fresh weight.

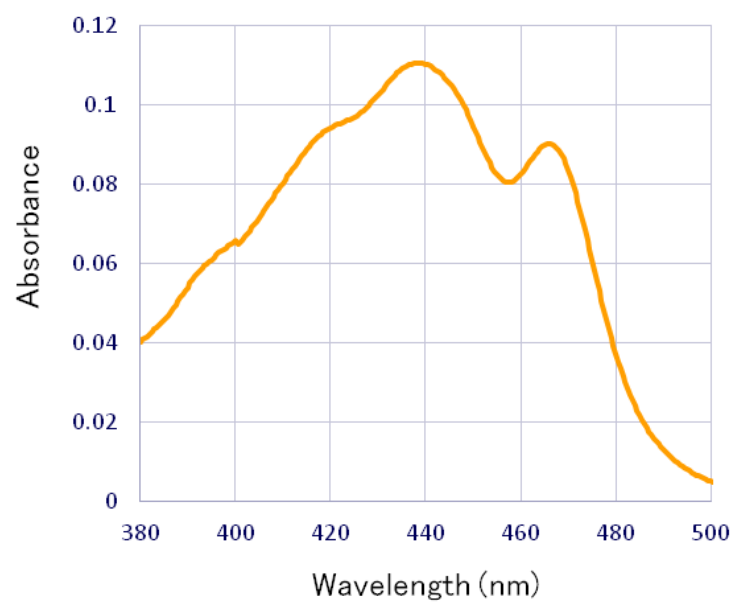

Figure 6. Absorption spectrum of hexane extracts of yellow callus of Avicennia alba.

\subsection{Ultrastructures of Carotenoid-containing Yellow A. alba Callus}

As shown in the Figure 7a, electron dense crystalloids and particle structures were found in the plastid with some starch granules of yellow A. alba callus under the transmission electron microscope. Electron dense aggregates were occasionally observed in vacuole (Figure 7b).
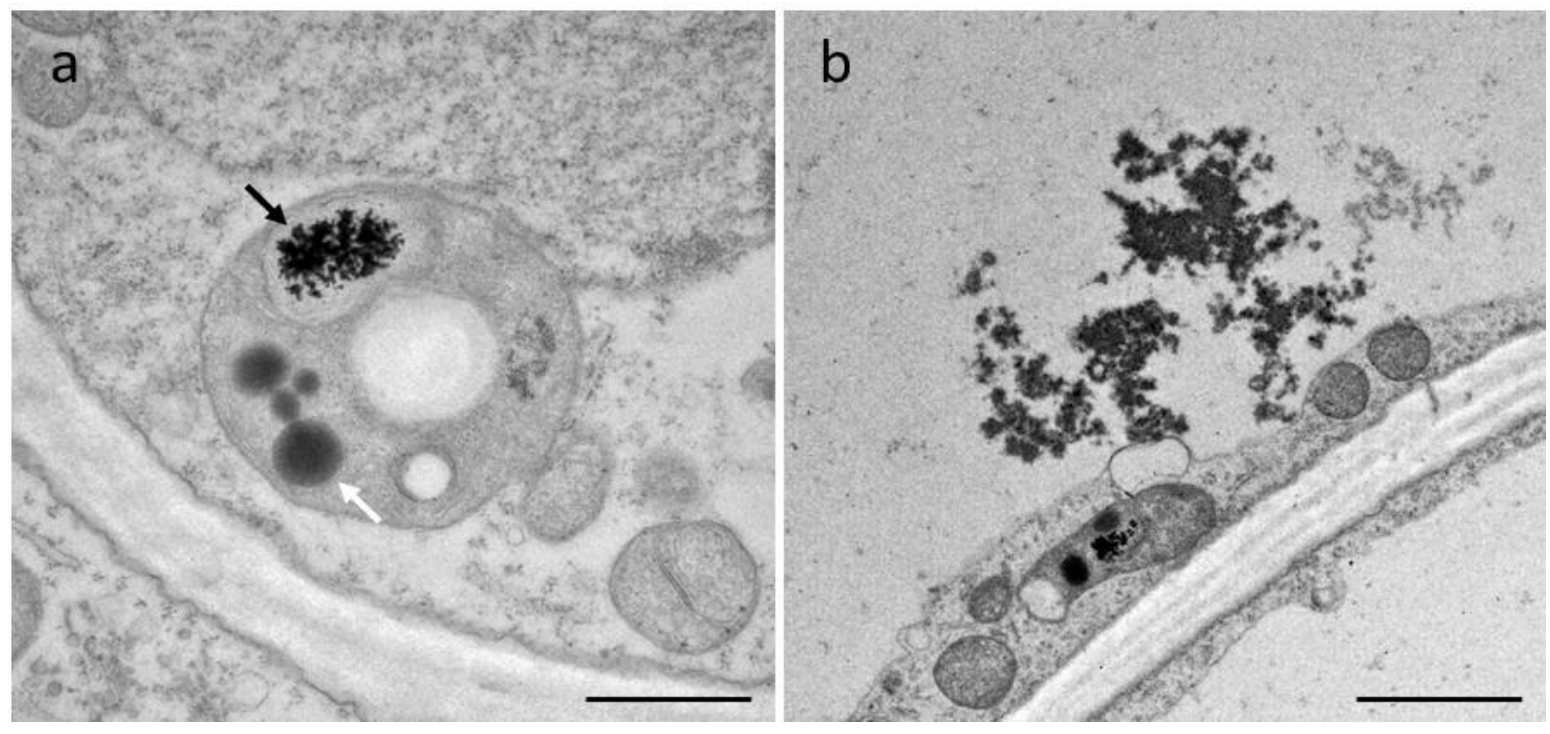

Figure 7. Electron microscope images of yellow callus of Avicennia alba. a: Plastids found in callus cells, including electron dense particles (white arrow) and crystalloids (black arrow) with some starch grains. b:

Electron dense aggregates in vacuole. Bar $=1 \mu \mathrm{m}$ (a) and $2 \mu \mathrm{m}$ (b).

\section{Discussion}

\subsection{Protoplast Isolation of Yellow A. alba Callus}

Protoplasts were isolated in the same enzyme combination, Cellulase RS and Driselase, in 0.6 M mannitol as of 
the original non-yellow callus of $A$. alba originating from hypocotyls (Tsuchiya et al., 2013). The protoplasts were also purified by sucrose density gradient centrifugation on $0.6 \mathrm{M}$ sucrose. The same combination of cell wall degrading enzymes, was applicable for the cotyledon-origin suspension-cultured cells (Hasegawa et al. 2011, 2013), though the osmotic conditions were different in the latter cells (1.2 M sorbitol). The same enzyme combination was also used for other Avicennia mangrove species (Sasamoto et al., 1997).

Although the yellow color was distinct in the concentrated protoplasts solution of yellow A. alba callus, in individual protoplast, the yellow color was undetectable under an inverted microscope. In a protoplast of engineered citrus callus, which showed high carotenoids content, the orange structure was detected by light microscopy (Cao et al., 2012). The A. alba protoplasts were similar in size as the original hypocotyls callus cultures, which varied from 20 to $60 \mu \mathrm{m}$ diameters (Tsuchiya et al. 2013).

\subsection{Difference of the Effects of Four Salts on the Protoplasts Growth of A. alba and Lettuce}

As shown in Figure 2, at the cell division stage of the protoplast culture of yellow A. alba callus, halophilic nature to $\mathrm{NaCl}$ was confirmed. Furthermore, halophilism to $\mathrm{KCl}$ and $\mathrm{MgCl}_{2}$ was also observed, but $\mathrm{CaCl}_{2}$ effect was inhibitory. Such inhibition by $\mathrm{Ca}^{2+}$ ions was also obtained at the early cell wall formation stage, and in protoplast culture of cotyledon-origin suspension cells of $A$. alba under a high osmotic culture condition (Hasegawa et al., 2013).

By contrast, lettuce cotyledons protoplast showed totally different patterns of salts effects as shown in Figure 3 . $\mathrm{NaCl}$ and $\mathrm{KCl}$ inhibited both cell wall formation and cell divisions. However, stimulation of growth was observed at low concentrations (10-25 mM) of $\mathrm{MgCl}_{2}$ and $\mathrm{CaCl}_{2}$. Such stimulation of protoplast growth at low concentrations of divalent cations was also seen in protoplast cultures of salt-tolerant mangrove, Bruguiera sexangula suspension cells (Fukumoto et al., 2004). Such results are different from those obtained with protoplasts cultures of non-salt tolerant poplar leaf, and tobacco BY-2 cells, which showed inhibition by all four salts in a $\mathrm{Cl}^{-}$ion-dependent manner (Fukumoto et al. 2004).

Very different from those of cell wall formation or cell division stages, yellow accumulation in lettuce protoplasts after one month of culture was inhibited in a $\mathrm{Cl}^{-}$ion-dependent manner, though inhibition by $\mathrm{NaCl}$ was slight. Yellow color can be observed in both non-spherically enlarged and divided protoplasts of lettuce under an inverted microscope. However, the yellow values are high at high protoplast densities and can be quantified after only 3 weeks of lettuce protoplast culture using Image J analysis (Ogita \& Sasamoto 2017), and the $\%$ of control values did not change during long culture period as reported (Sasamoto et al. 2017a,b). The yellow color of lettuce protoplasts was extracted using Triton X-100, and a carotenoid, $\beta$-zeacarotene was spectrophotometrically suggested (Sasamoto et al., 2017a). This yellow pigment accumulation phenomenon after about one month of culture is used for the bioassay method of allelopathy, the protoplast co-culture with the digital image analysis (Ogita \& Sasamoto, 2017; Sasamoto et al., 2017a,b, 2018, 2019).

Therefore, yellow A. alba callus showed halophilic nature for cell divisions in protoplast cultures, in the same medium condition as with lettuce protoplasts. These findings are the same as those of non-yellow cotyledon-origin suspension cells of $A$. alba cultured in the dark, though the high osmotic medium was used in the latter A. alba cells (Hasegawa et al., 2013).

\subsection{Strong Allelopathic Activities of Yellow A. alba Callus: Protoplast Co-culture with Digital Image Analysis}

The effects of protoplasts of yellow A. alba callus on the three different stages of lettuce protoplast growth were investigated using the protoplast co-culture method (Figure 5). After 5 days of co-culture, at early cell wall formation stage of lettuce protoplasts, stimulation by A. alba protoplasts was prominent up to $10^{5} \mathrm{~mL}^{-1}$ and rapid reduction of growth was seen at high density, $3 \times 10^{5} \mathrm{~mL}^{-1}$.

Strong inhibition was observed at the cell division stage of lettuce protoplast growth after 12 days of co-culture. There was less than $50 \%$ and $10 \%$ growth of control at $10^{4} \mathrm{~mL}^{-1}$ and at $5 \times 10^{4} \mathrm{~mL}^{-1}$, respectively, with A. alba, which was similar to the findings reported for upstream grown mangrove species, e.g., Sonneratia caseolaris (Hasegawa et al., 2014) and Derris indica (Inoue et al., 2015). The mangrove plant, S. ovata grows in-between of seaward-side grown $S$. alba and $S$. caseolaris. An inverse relationship was reported between salt tolerance and allelopathic activities of these three Sonneratia species (Hasegawa et al., 2014). The inhibitory activity of yellow A. alba protoplasts was stronger at both protoplast densities than that of protoplasts of $S$. ovata suspension cells grown in the dark (Hasegawa et al., 2014).

Protoplasts of red callus of $S$. ovata, which were sub-cultured in the light condition, had stronger inhibitory at the cell division stage, at $10^{4} \mathrm{~mL}^{-1}$, than those of dark-grown suspension cells. The allelochemical of $S$. ovata red callus was clarified as an anthocyanin, cyanin (Sasamoto et al., 2018). 
Inhibition of yellow pigment accumulation of lettuce protoplasts by $A$. alba protoplasts was investigated using digital image analysis of scanned 96-well culture plates after 33 days of co-culture. Less inhibition by A. alba protoplasts was observed at the yellow pigment accumulation stage compared with those at the cell division stage of lettuce growth (Figure 5). Less inhibition \% of control on yellow pigment accumulation of lettuce protoplasts than on cell division was reported for several plant materials, e.g., Arabidopsis thaliana (Sasamoto et al. 2017b), bamboo species (Ogita \& Sasamoto, 2017), Vicia villosa (Sasamoto et al. 2019), and putative allelochemicals tested. Inhibition at $10^{5} \mathrm{~mL}^{-1}$ by A. alba protoplasts (about $50 \%$ growth of control) was similar to that of A. thaliana (40\%) but less than that of V. villosa (30\%) and Sasa kurilensis (0\%). By contrast, no inhibition of yellow pigment accumulation by protoplasts of red $S$. ovata callus and the allelochemical anthocyanin, cyanin, had been reported (Sasamoto et al., 2018).

Such results suggest that specific allelochemical(s) contained in the test plant protoplasts cause the specific inhibition patterns at the three stages of growth of recipient lettuce protoplasts. However, there may be a different cellular mechanism(s) among test plant cells to recipient plant cells and different uptake efficiency of chemicals supplied in protoplast culture medium. Therefore, the inhibitory effects at the cell division stage of lettuce are basic criteria of allelopathic activities of test plants.

\subsection{Salt Tolerance and Allelopathic Activity in Mangrove Plant Cells}

An inverse relationship has been found between allelopathic activity and salt tolerance at both plant level and cellular level in several mangrove species, which can grow at most seaward-side ( $S$. alba), in-between $(B$. sexangula; S. ovata) and upstream area (Derris indica; S. caseolaris) in brackish water (Hasegawa, 2014; Hasegawa et al., 2014; Sasamoto \& Hasegawa, 2014; Sasamoto et al., 2014; Inoue et al., 2015). Such an inverse relationship between halophilism or high salt tolerance and strong allelopathic activities might be seen in different mangrove plant species (Hasegawa, 2014; Sasamoto et al., 2014).

Avicennia mangrove, A. alba, which grows on the seaward-side of brackish water, showed halophilic nature at the cellular level using suspension-cultured cells (Hasegawa et al., 2013), but not for their allelopathic activities before. Here, we confirmed the strong halophilic nature of protoplast culture of yellow A. alba callus (section 3.2), compared with non-salt tolerant lettuce protoplast culture (section 3.3). This is the first report on an Avicennia mangrove using protoplast co-culture bioassay of allelopathy with digital image analysis. Unexpectedly, yellow A. alba callus cultured in the dark showed strong inhibitory allelopathic activities (section 3.4).

The red callus of $S$. ovata, which was sub-cultured in the light, had stronger allelopathic activity than the dark-grown suspension cells. An anthocyanin, cyanin, was found in the red callus and was evaluated as an allelochemical (Sasamoto et al., 2018).

These findings suggested that the yellow substance(s) in the yellow A. alba callus with halophilic nature might be responsible for the high inhibitory allelopathic activity of their protoplasts.

\subsection{Spectrophotometry and Transmission Electron Microscopy of Carotenoid Crystalloids in Yellow A. alba Callus}

The yellow substance in A. alba callus was identified spectrophotometrically as neoxanthin. The same absorption spectrum of standard neoxanthin was also reported (9'-cis-neoxanthin, Takaichi et al. 2006). The content in the callus was about 4 nmoles / $\mathrm{g}$ fresh weight (section 3.5) which is comparable to that of carotenoid-containing calluses previously reported. The content of $\beta$-carotene, in wild type Citrus callus was 0.3-13 $\mu \mathrm{g}$ (24 nmoles)/g dry weight (Cao et al., 2012), and in carotenoid-containing carrot callus cultured in the dark it was 200-2000 $\mu \mathrm{g}$ (4 $\mu$ moles) /g dry weight (Oleszkiewicz et al., 2018).

Electron dense crystalloids and particle structures were found in the plastid of yellow A. alba callus using transmission electron microscopy (section 3.6). Such structures in the plastid were not observed in non-yellow A. alba suspension cells originating from cotyledons (Hayatsu et al., 2017). During fruit ripening, many electron dense particle structures, plastoglobuli, and more developed plate-like crystalloids in chromoplasts were found in carotenoid-containing plant tissues (Aoki et al., 2011; Hayatsu et al., 2016; Suzuki, 2017). Undeveloped ultrastructure of a carotenoid in chromoplast, was also reported in a $\beta$-carotene-containing carrot root callus cultured in the dark (Oleszkiewicz et al., 2018). Similar electron dense particle structures in the vacuole were also reported as plastoglobules of a carotenoid in the engineered dark-grown Citrus callus (Cao et al., 2012). We also observed an electron dense aggregate structure in the vacuole, but further study is needed to clarify the natural existence of carotenoids in the vacuole. 


\subsection{Carotenoid as a Putative Allelochemical in Yellow Callus of A. alba}

Carotenoids along with chlorophylls pigments are the photosynthetic apparatus in the light condition (Takaichi et al., 2006; Aoki et al., 2011). However, the yellow A. alba callus was sub-cultured in the dark for a long period. The biosynthetic pathway of a plant hormone, abscisic acid (ABA), is related to that of carotenoids. 9'-cis neoxanthin in chloroplasts is a precursor of cis-ABA, which is a growth retardant and related to stress tolerance, such as salt tolerance. For example, growth inhibition of cotyledon-origin suspension cells of A. alba by the addition of ABA in the protoplast culture medium was caused by the endogenous levels of cis-ABA (3.7 to 43 pmoles $/ 6 \times 10^{6}$ protoplasts, Hasegawa et al., 2011). In another mangrove plant, Kandelia obovata, high content of cis-ABA in leaf protoplasts was reported for the cause of recalcitrancy of callus growth (Kaai et al., 2008).

In the protoplast culture of Prunus yedoensis, which has a cis-ABA content of 34 pmoles $/ 10^{7}$ protoplasts, growth was strongly inhibited by exogenous ABA supply, while their growth was not inhibited by another putative allelochemical, coumarin, the content of which was 22 nmoles / g fresh weight. However, exogenously supplied ABA at up to $10 \mu \mathrm{M}$ stimulates the growth of lettuce protoplasts (Sasamoto et al. 2013). ABA was not likely the allelochemical of $P$. yedoensis in protoplast co-culture with the recipient lettuce protoplasts, since $P$. yedoensis had a low ABA content, but coumarin was likely an allelochemical in the co-culture with lettuce protoplasts (Fujise et al., 2018). Similarly, ABA was probably not the allelochemical of A. alba in protoplast co-culture with the recipient lettuce protoplasts, since A. alba had a low ABA content. The effects of carotenoid might not be directly related to cis-ABA synthesis.

Though, the function of carotenoids in the allelopathic activity remains unknown, our findings strongly suggest that a carotenoid pigment functions as an allelochemical in the dark-grown halophillic mangrove plant cells. And they led the examination of allelopathic activities of different carotenoids ( $\beta$-carotene, neoxanthin, crocin) in culture medium using the protoplast co-culture bioassay method of allelopathy with digital image analysis (Suzuki et al., 2019).

\section{References}

Aoki, Y., Ono, M., Hayatsu, M., \& Suzuki, S. (2011). Changes of pigments and plastid ultrastructures in the pericarp during fruit ripening of Aucuba japonica Thunb. Science Journal of Kanagawa University, 22, 63-70.

Bergum, K., Shammi, M., Hasan, N., Asaduzzaman, M., Appiah, K. S., \& Fujii, Y. (2019). Potential allelopathic candidates for land use and possible sustainable weed management in south asian ecosystem. Sustainability, 11, 2649. https://doi.org/10.3390/su11092649

Cao, H., Zhang, J., Xu, J., Ye, J., Yun, Z., Xu, Q., Xu, J., \& Deng, X. (2012) Comprehending crystalline $\beta$ -carotene accumulation by comparing engineered cell models and the natural carotenoid-rich system of citrus. Journal of Experimental Botany, 63, 4403-4417. https://doi.org/10.1093/jxb/ers115

Davies, B. H. (1965). Analysis of carotenoid pigments. In: Chemistry and Biochemistry of Plant Pigments. Goodwin T. W., ed., Academic Press, London \& New York. pp. 489-532.

Fujii, Y. (2000). Allelopathy, Nobunkyo, Tokyo.

Fujii, Y., Parvez, S. S., Parvez, M. M., Ohmae, Y., \& Iida, O. (2003). Screening of 239 medicinal plant species for allelopathic activity using the sandwich method. Weed Biology and Management, 3, 233-241. https://doi.org/10.1046/j.1444-6162.2003.00111.x

Fujise, K., Yokota, S., \& Sasamoto, H. (2018). Evaluation of allelochemicals, abscisic acid and coumarin, in leaf-origin suspension cultured cells of Prunus yedoensis using protoplast co-culture bioassay method. American Journal of Plant Sciences, 9, 172-184. https://doi.org/10.4236/ajps.2018.92015

Fukumoto, T., Nakamura, T., Suzuki, M., Ogita, S., Mimura, T., \& Sasamoto, H. (2004). Different effects of four salts and pHs on protoplast cultures of a mangrove, Bruguiera sexangula suspension cells, Populus alba leaves and tobacco BY-2 cells. Plant Biotechnology, 21, 177-182.

https://doi.org/10.5511/plantbiotechnology.21.177

Hasegawa, A. (2014). Research on the relationship between salts tolerance and allelopathy at the cellular level in mangrove plants. Ph.D. thesis of Yokohama National University. pp. 1-124.

Hasegawa, A., Hayashi, S., Kurita, A., Kaai, F., Kawana, Y., Fukumoto, T., \& Sasamoto, H. (2011). Stimulatory and inhibitory effects of abscisic acid on cell growth in protoplast cultures and the relation to its endogenous levels in Avicenniaceae mangrove cells. Mangrove Science, 8, 11-18. 
Hasegawa, A., Kurita, A., Hayashi, S., Fukumoto, T., \& Sasamoto, H. (2013). Halophilic and salts tolerant protoplast cultures of mangrove plants, Sonneratia alba and Avicennia alba, Plant Biotechnology Reports, 7, 205-209. https://doi.org/10.1007.s11816-012-0251-2

Hasegawa, A., Oyanagi, T., Minagawa, R., Fujii, Y., \& Sasamoto, H. (2014). An inverse relationship between allelopathic activity and salt tolerance in suspension cultures of three mangrove species, Sonneratia alba, $S$. caseolaris and S. ovata: Development of a bioassay method for allelopathy, the protoplast co-culture method. Journal of Plant Research, 127, 755-761. https://doi.org/10.1007/s10265-014-0651-1

Hayashi, S., Kuriyama, S., Kawana, Y., Hasegawa, A., Kurita, A., Minagawa, R., \& Sasamoto, H. (2009). Stimulatory effects of sea salts on cell growth in liquid culture of Avicenniaceae mangrove. Plant Biotechnology, 26, 561-564. https://doi.org.10.5511.plantbiotechnology.26.561

Hayatsu, M., Suzuki, S., Hasegawa, A., Tsuchiya, S., \& Sasamoto, H. (2014). Effect of $\mathrm{NaCl}$ on ionic content and distribution in suspension-cultured cells of the halophyte Sonneratia alba versus the glycophyte Oryza sativa. Journal of Plant Physiology, 171, 1385-1391. http://dx.doi.org/10.1016/j.jplph.2014.06.008

Hayatsu, M., Sato, M., \& Suzuki, S. (2016). Pigment changes and chromoplast morphogenesis in pericarp during fruit ripening of Trichosanthes cucumeroides Maxim. Science Journal of Kanagawa University, 27, 45-51.

Hayatsu, M., Suzuki, S., Tsuchiya, S., \& Sasamoto, H. (2017). Cellular calcium distribution modulates the growth of callus and protoplasts of halophyte mangrove plant, Avicennia alba- an X-ray microanalysis. Journal of Plant Studies, 6, 18-27. https://doi.org/10.5539/jps.v6n2p18

Inoue, A., Mori, D., Minagawa, R., Fujii, Y., \& Sasamoto, H. (2015). Allelopathy in a leguminous mangrove plant, Derris indica: Protoplast co-culture bioassay and rotenone effect. Natural Product Communications, 5, 747-750. https://doi.org/10.1177/1934578X1501000512

Kaai, F., Kawana, Y., \& Sasamoto, H. (2008). The relation between recalcitrancy of a mangrove plant, Kandelia obovata, and high endogenous level of abscisic acid. Plant Cell Tissue and Organ Culture, 94, 125-130. https://doi.org/10.1007/s11240-008-9394-9

Kawana, Y., \& Sasamoto, H. (2008). Stimulation effects of salts on growth in suspension culture of a mangrove plant, Sonneratia alba, compared with another mangrove, Bruguiera sexangula and non-mangrove tobacco BY-2 cells. Plant Biotechnology, 25, 151-155. https://doi.org/10.5511/plantbiotechnology.25.151

Mori, D., Ogita, S., Fujise, K., Inoue, A., \& Sasamoto, H. (2015). Protoplast co-culture bioassay for allelopathy in leguminous plants, Leucaena leucocephala and Mucuna gigantea, containing allelochemical amino acids, mimosine and L-DOPA. Journal of Plant Studies, 4, 1-11. https://doi.org/10.5539/jps.v4n1p1

Murashige, T., \& Skoog, F. (1962). A revised medium for rapid growth and bio assays with tobacco tissue cultures. Physiologia Plantarum, 15, 473-497. https://doi.org/10.1111/j.1399-3054.1962.tb08052.x

Ogita, S., \& Sasamoto, H. (2017). In vitro bioassay of allelopathy in four bamboo species; Bambusa multiplex, Phyllostachys bambusoides, P. nigra, Sasa kurilensis, using sandwich method and protoplast co-culture method with digital image analysis. American Journal of Plant Sciences, 8, 1699-1710. https://doi.org/10.4236/ajps.2017.87117

Oleszkiewicz, T., Klimek-Chodacka, M., Milewska-Handel, A., Zubko, M., Stroz, D., Kurczynska, E., Boba, A., Szopa, J., \& Baranski, R. (2018). Unique chromoplast organization and carotenoid gene expression in carotenoid-rich carrot callus. Planta, 248, 1455-1471. https://doi.org/10.1007//s00425-018-2988-5

Rasband, W. S. (1997-2016). Image J.U.S. National Institute of Health, Bethesda, Maryland, USA. Retrieved from http://imagej.nih.gov/ij

Sasamoto, H., \& Ashihara, H. (2014). Effect of nicotinic acid, nicotinamide and trigonelline on the proliferation of lettuce cells derived from protoplasts. Phytochemistry Letters, 7, 38-41. https://doi.org/10.1016/j.phytol.2013.09.008

Sasamoto, H., \& Hasegawa, A. (2014). In vitro bioassay of allelopathy in mangrove plants. Abstract of the $20^{\text {th }}$ Annual Meeting of Japan Society for Mangroves, pp. 9.

Sasamoto, H., Wakita, Y., \& Baba, S. (1997). Effect of high sorbitol concentration on protoplast isolation from cotyledons of mangroves, Avicennia marina, and A. lanata. Plant Biotechnology, 14, 101-104. http://dx.doi.org/10.5511/plantbiotechnology.14.101

Sasamoto, H., Murashige-Baba, T., Inoue, A., Sato, T., Hayashi, S., \& Hasegawa, A. (2013). Development of a new method for bioassay of allelopathy using protoplasts of a leguminous plant Mucuna pruriens with a 
high content of the allelochemical L-DOPA. Journal of Plant Studies, 2, 71-80. https://doi.org/10.5539/jps.v2n2p71

Sasamoto, H., Hasegawa, A., Mochida, Y., Yokota, S., Minagawa, R., \& Fujii, Y. (2014). In vitro bioassay of allelopathy in mangrove species and Populus and Betula species: Sandwich method and protoplast co-culture method. Proceeding of the $78^{\text {th }}$ Annual Meeting of the Botanical Society of Japan, pp. 238.

Sasamoto, H., Fujii, Y., \& Ashihara, H. (2015a). Effect of purine alkaloids on the proliferation of lettuce cells derived from protoplasts. Natural Product Communications, 5, 751-754. https://doi.org/10.1177/1934578X1501000513

Sasamoto, H., Azumi, Y., \& Suzuki, S. (2017a). Development of a high-throughput bioassay method of allelopathy-Protoplast co-culture and digital image analysis. Science Journal of Kanagawa University, 28, 63-70.

Sasamoto, H., Azumi, Y., Shimizu, M., Hachinohe, Y., \& Suzuki, S. (2017b). In vitro bioassay of allelopathy of Arabidopsis thaliana by sandwich method and protoplast co-culture method with digital image analysis. Plant Biotechnology, 34, 199-202. https://doi.org/10.5511/plantbiotechnology.17.1204a

Sasamoto, H., Iwashina, T., Suzuki, S., Azumi, Y., \& Fujii, Y. (2018). Evaluation of an anthocyanin, cyanidin3,5-di- $O$-glucoside,as an allelochemical in red callus of a mangrove Sonneratia ovata, using protoplast co-culture bioassay method with digital image analysis. Journal of Plant Studies, 7, 1-10. https://doi.org/10.5539/jps.v7n2p1

Sasamoto, H., Mardani, H., Sasamoto, Y., Wasano, N., Murashige-Baba, T., Sato, T., Hasegawa, A., \& Fujii, Y. (2019). Evaluation of canavanine as an allelochemical in etiolated seedlings of Vicia villosa Roth: protoplast co-culture method with digital image analysis. In Vitro Cellular \& Developmental Biology-Plant, 55, 296-304. https://doi.org/10.1007/s11627-019-09985-3

Spalding, M., Kainuma, M., \& Cocking, E. C. (2010). World Atlas of Mangroves. Earthscan, UK and USA. https://doi.org/10.4324/9781849776608

Suzuki, S. (2017). Pigment changes and chromoplast morphogenesis during the plant organ maturation. Science Journal of Kanagawa University, 28(2), 361-365.

Suzuki, S., Sasamoto, H., Mardani, H., Sasamoto, Y., \& Fujii, Y. (2019). In vitro bioassay of allelopathic activities of carotenoids using protoplast co-culture method with digital image analysis. Abstracts of the $37^{\text {th }}$ Annual Meeting of the Japanese Society for Plant Cell and Molecular biology, pp. 138.

Takaichi, S., Mimuro, M., \& Tomita, Y. (2006). Carotenoids, Biological Functions and Diversity. Shokabo, Tokyo.

Thompson, J. A., Abdullah, R., \& Cocking, E. C. (1986). Protoplast culture of rice (Oryza sativa) using media solidified with agarose. Plant Science, 47, 123-133. https://doi.org/10.1016/0168-9452(86)90059-2

Tomlinson, P. B. (1986). The Botany of Mangroves. Cambridge University Press, New York.

Tsuchiya, S., Ogita, S., Kawana, Y., Oyanagi, T., Hasegawa, A., \& Sasamoto, H. (2013). Relation between amino acids profiles and recalcitrancy of cell growth or salt tolerance in tissue and protoplast cultures of three mangrove species, Avicennia alba, Bruguiera sexangula, and Sonneratia alba. American Journal of Plant Sciences, 4, 1366-1374, https://doi.org/10.4236/ajps.2013.47167

Yamamoto, R., Kawana, Y., Minagawa, R., \& Sasamoto, H. (2011). Effects of sea salts on induction of cell proliferation in liquid cultures of mangrove plants, Sonneratia caseolaris and S. alba. American Journal of Plant Sciences, 2, 35-42. https:// doi.org/10.4236/ajps.2011.21004

\section{Copyrights}

Copyright for this article is retained by the author(s), with first publication rights granted to the journal.

This is an open-access article distributed under the terms and conditions of the Creative Commons Attribution license (http://creativecommons.org/licenses/by/3.0/). 